\title{
LA GEOPOLÍTICA DEL PROGRESISMO LATINOAMERICANO Y EL VOLUNTARISMO DE SUS CRÍTICOS DE IZQUIERDA.
}

\author{
Jorge Hugo GONZÁLEZ PAREDES ${ }^{1}$ \\ Carlos FIGUEROA IBARRA ${ }^{2}$
}

\begin{abstract}
Resumen
A partir de 1999 con Hugo Chávez Latinoamérica empezó a observar una oleada de triunfos y gobiernos posneoliberales que aparentemente terminaría en diciembre de 2015 con el triunfo de Mauricio Macri en Argentina. En este trabajo examinaremos las críticas a los gobiernos progresistas que provienen de las distintas vertientes de la izquierda: la izquierda posextractivista/posdesarrollista, la izquierda autonomista, y la izquierda doctrinaria con horizonte socialista. Sostenemos que estas críticas ignoran la correlación de fuerzas que tienen dichos gobiernos en el contexto mundial que ha emergido después del derrumbe soviético, el multipolarismo por la presencia de Rusia y China además de Estados Unidos, la geopolítica del progresismo latinoamericano ubicado en el área hegemónica estadounidense y la historia extractivista latinoamericana en el contexto de una añeja división internacional del trabajo.
\end{abstract}

Palabras claves: Geopolítica, posneoliberalismo, izquierda, extractivismo, dependencia.

\begin{abstract}
Abstrac
Since 199 when Hugo Chávez won the presidency of Venezuela, began a wave of posneoliberal governments in Latin America. This wave aparently was finished on December of 2015 with the triumph of Mauricio Macri in Argentina. In this paper we explore the criticism about the progressive goverments since the horizon of different perspectives from the left: the posextractivist/posdevelopmentist left, the autonomist left and the doctrinaire left with socialist horizon. We maintain that this criticism ignore the

\footnotetext{
${ }^{1}$ Doctor en Sociología, Profesor investigador en la Licenciatura en Economía de la Benemérita Universidad Autónoma de Puebla (BUAP).

${ }^{2}$ Doctor en Sociología,_Profesor investigador en el Posgrado de Sociología del Instituto de Ciencias Sociales y Humanidades “Alfonso Vélez Pliego" de la BUAP.
}

Fecha de recepción del artículo: Agosto 2021

Fecha de evaluación: Octubre 2021 
balance of forces in the world context emerged after the soviet colapse, the multipolarism generated with the emergency of Russia and China and United States of America, the geopolitics of Latin American progressivism inside the área of influence of Washington and the Latin American extractivist history in the context of an ancient international división of labour.

Keywords: Geopolitics, post-neoliberalism, left, extractivism, dependency.

\section{Résumé}

À partir de 1999 avec Hugo Chávez, l'Amérique latine a commencé à observer une vague de triomphes et de gouvernements post-néolibéraux qui se termineraient apparemment en décembre 2015 avec le triomphe de Mauricio Macri en Argentine. Dans cet article, nous examinerons les critiques des gouvernements progressistes qui proviennent des différents aspects de la gauche : la gauche post-extractiviste/post-développementiste, la gauche autonomiste et la gauche doctrinaire à horizon socialiste. Nous soutenons que ces critiques ignorent la corrélation de forces que ces gouvernements ont dans le contexte mondial qui a émergé après l'effondrement soviétique, le multipolarisme dû à la présence de la Russie et de la Chine ainsi que les États-Unis, la géopolitique du progressisme latino-américain situé dans la zone hégémonique américaine et l'histoire extractiviste latino-américaine dans le contexte d'une division internationale du travail de longue date. Mots-clés : Géopolitique, post-néolibéralisme, gauche, extractivisme, dépendance.

\section{Introducción.}

En los primeros tres lustros del siglo XXI, América Latina vivió las consecuencias de las promesas incumplidas del neoliberalismo. En vez de una productividad que iría anegando de prosperidad a la sociedad, la acumulación neoliberal y sus recurrentes crisis provocaron un crecimiento de la desigualdad y de la pobreza. América Latina fue el único lugar del mundo en donde los efectos de las recurrentes crisis originaron movimientos sociales y/o políticos que se convirtieron en movimientos político-electorales y en eventuales gobiernos de izquierda $y$ de centro izquierda, hoy llamados convencionalmente gobiernos progresistas.

Paulatinamente la mayor parte de la geografía latinoamericana presenció la asunción de gobiernos con mayor o menor voluntad posneoliberal. La asunción en 1999 de Hugo Chávez Frías como presidente de Venezuela fue sucedida en Brasil por Lula Da Silva (enero de 2003), por Néstor Kirchner en Argentina (mayo de 2003), Tabaré Vázquez en Uruguay (2005), Evo Morales en Bolivia y José Manuel Zelaya en Honduras (enero de 2006), Rafael Correa en Ecuador y Daniel Ortega en Nicaragua (enero de 2007), Fernando Lugo en Paraguay (2008), Mauricio Funes en El Salvador (2009). En Brasil, Argentina, Uruguay, Bolivia, Ecuador, Nicaragua y El Salvador los gobiernos progresistas perduraron a través de reelecciones o sucesiones. En Honduras y Paraguay 
fueron derrocados en 2009 y 2012 respectivamente. Finalmente a partir de las elecciones presidenciales en Argentina de diciembre de 2015 cuando el kirchnerismo fue derrotado, los gobiernos progresistas entraron en un reflujo con un golpe de estado en Brasil (2016) y el encarcelamiento de Lula (2018), el giro neoliberal de Lenín Moreno en Ecuador (2017) y la derrota electoral del FMLN en EL Salvador (2019). Pero el progresismo ha dado muestras de no estar acabado: lo muestran hechos como el triunfo de Andrés Manuel López Obrador en 2018, el de Alberto Fernández en Argentina en 2019, el triunfo constituyente en Chile y la victoria de Luis Arce en Bolivia en octubre de 2020.

Todos estos gobiernos han sufrido un embate feroz desde la derecha neoliberal y neofascista. Sin embargo, en este trabajo no nos centraremos en examinar las críticas que desde la derecha se le han hecho al progresismo latinoamericano. Examinaremos las que provienen de las distintas vertientes de la izquierda que básicamente son la izquierda posextractivista/posdesarrollista, la izquierda autonomista, y la izquierda con horizonte socialista. Sostenemos que las mismas están fundadas en un análisis unilateral y a menudo abstracto del contexto mundial y regional en el cual han surgido los gobiernos progresistas. En las críticas referidas, subyace una dosis de voluntarismo que ignora la correlación de fuerzas determinadas por el contexto mundial en el que las experiencias progresistas se han desenvuelto. Argumentamos que dicha correlación de fuerzas emergida en el mundo después del derrumbe soviético está marcada por los límites que imponen a la acción transformadora de los gobiernos progresistas los siguientes hechos: la transición del mundo unipolar al multipolar con actores como Rusia y China además de Estados Unidos, la propia situación geopolítica de los gobiernos progresistas latinoamericanos ubicados en el área hegemónica estadounidense, la historia extractivista de América Latina en el contexto de una añeja división internacional del trabajo.

\section{Confundiendo el deseo con la realidad: las críticas de izquierda al progresismo.}

En un aforismo sumamente conocido parafraseando a Romain Rolland, Antonio Gramsci aseveró acerca de las bondades del "pesimismo de la inteligencia y el optimismo de la voluntad" (Gramsci, 1985: 139). Es con éste espíritu que examinamos las críticas que desde la izquierda se le han hecho a los gobiernos posneoliberales. Partimos de la base de que la voluntad subjetiva es la fuente de la transformación social pero también que dicha voluntad está acotada por las condiciones objetivas. Nuestra crítica a buena parte de las críticas que desde la izquierda se han hecho a los gobiernos progresistas, es que confunden deseos con realidad y unilateralizan el papel de la voluntad en el cambio social. Sostenemos que los gobiernos progresistas no unilateralizan el pesimismo de la inteligencia (Garrido, 2015) sino lo complementan con el optimismo de la voluntad.

a. El embate posdesarrollista y posextractivista. 
Para la izquierda posdesarrollista/posextractivista la causa que permitiría explicar el agotamiento del ciclo progresista en América Latina sería la profundización del extractivismo que impulsaron los gobiernos de izquierda. La esencia del neoextractivismo progresista radicaría en el papel del Estado para tener un fuerte control sobre la explotación de los recursos naturales y obtener una mayor participación sobre las rentas obtenidas. Con estos excedentes se impulsó el crecimiento económico a través de la inversión pública y mejoró la redistribución de la riqueza a través de programas asistencialistas y subvenciones para disminuir el desempleo y la pobreza (Gudynas, 2011 :90). Sin embargo, al no modificar la base extractivista se reprodujeron los mismos males del extractivismo clásico: escasos o nulos encadenamientos de la planta productiva, déficits en cuenta corriente que obligan al endeudamiento externo, daños irreversibles en el medio ambiente; concentración de la riqueza en pocas manos; así como la creación de una mentalidad rentista que fomenta el consumismo (Acosta, 2011: 101-103).

En el ámbito político -continúa la argumentación de esta vertiente de la izquierda-, el neoextractivismo progresista vulneró la democracia al imponer regímenes hiperpresidencialistas, caudillistas y autoritarios que hicieron un uso discrecional de los recursos públicos, alentaron el clientelismo, la corrupción y no escatimaron en utilizar la fuerza y la violencia para criminalizar y reprimir la protesta social. El principal problema de los gobiernos progresistas es que no lograron superar el paradigma del desarrollo en términos capitalistas que se sustenta en la técnica, el progreso material y el uso indiscriminado e irracional de los recursos naturales para favorecer el crecimiento económico que aparentemente no tendría limites naturales (Gudynas, 2011:38). La propuesta de la izquierda posextractivista/posdesarrollista es que habría que ir más allá del desarrollo. La alternativa consistiría en implementar un proyecto postextractivista que redujera sustancialmente el consumo de materia y energía, impulsara actividades sustentables en la manufactura, la agricultura y el turismo recuperando las prácticas y cosmovisiones de los pueblos indígenas en la que los seres humanos conviven de manera armoniosa con la naturaleza: el buen vivir y el sumak kawsay (Gudynas, 2011: 33).

Aspecto cuestionable de la crítica posdesarrollista hacia los gobiernos progresistas es que se concentran en explicar las relaciones de poder que se encuentran detrás del discurso del desarrollo y la modernidad, pero ignora el conjunto de las relaciones internacionales de dependencia que condicionan el funcionamiento interno de las sociedades latinoamericanas. La nueva división internacional del trabajo que se establece a partir de las reconfiguraciones que experimenta el capitalismo en su etapa neoliberal actual, reprimariza a los países sudamericanos para que se incorporen al mercado global como abastecedores de materias primas. Derivado de lo anterior, la izquierda posdesarrollista cae en otra inconsistencia: no distinguen entre postulados lógicos y posibilidades empíricas al plantearse proyectos de transformación que pueden ser pensados sin contradicción en la teoría, pero que difícilmente pueden ser llevados a la realidad (Dussel, 2006: 129). Es decir, en su propuesta de implementar un proyecto posextractivista se tendrían que cumplir dos condiciones o al menos una de ellas. En primer lugar que cambien las relaciones internacionales de dependencia, lo cual implicaría la superación del capitalismo a escala global. O bien que los países con gobiernos progresistas se 
desconecten de la globalización para implementar un decrecimiento económico planificado del extractivismo. Ambas condiciones son imposibles en el corto y mediano plazo. También queda sin explicar la viabilidad que puede tener un proyecto posextractivista frente a una realidad en la que existen necesidades urgentes que cubrir en el corto plazo y que se complica por la fuerte presión que ejercen las oligarquías locales y el capital extranjero para recuperar el poder político y asegurar sus privilegios.

Por último, otro inconveniente del posdesarrollismo es que reproduce una vertiente del pensamiento posmoderno. Este es resaltar la diversidad cultural de los movimientos indígenas, campesinos y ambientalistas por encima de la unidad que hay detrás de las diferencias de las formas. En consecuencia queda sin importancia la unidad de la lucha y resistencia para enfrentar la dominación unificada del capital (Zizek, 2009: 169-189). El costo social que esto tiene es doble, por una parte producto de una desarticulación, los movimientos sociales quedan expuestos a reveses, y por otra, las demandas sectorializadas no alcanzan una unidad política alternativa a la dominante. Así las cosas, puede alejarse la propuesta de llegar a una sociedad posdesarrollista que conviva de manera armoniosa con la naturaleza.

\section{b. La crítica autonomista}

La izquierda autonomista plantea la hipótesis del fin de ciclo del posneoliberalismo porque sus gobiernos emprendieron una revolución pasiva para administrar el conflicto social, subalternizar a los movimientos sociales y mantener la reproducción del capitalismo dependiente sustentado en el extractivismo, el rentismo y la concentración de la riqueza (Modonesi, 2015: 23; Svampa, 2017). Estos gobiernos serían los directamente responsables de reprimarizar sus economías para cumplir con los requerimientos que impone la nueva división territorial y global del trabajo (Svampa, 2011: 185). Cierto es que estos gobiernos implementaron políticas económicas heterodoxas, retomaron demandas promovidas desde abajo e impulsaron la construcción de un espacio regional latinoamericano para superar el neoliberalismo. Pero también concentraron el poder político en unas cuantas personas e impidieron la renovación de liderazgos y se reeditaron formas históricas de dominación al subordinar a los actores colectivos al líder y el control estatal, fomentando la corrupción, el autoritarismo y el burocratismo (Svampa, 2017). La alternativa que propone la izquierda autonomista es construir un escenario posprogresista que recupere la capacidad de auto-organización y articulación de los movimientos indígenas en el campo y los movimientos populares-sindicales en la ciudad, superando la dicotomía entre continuidad progresista y restauración derechista (Modonesi \& Svampa, 2016).

La izquierda autonomista fractura la propuesta epistemológica de la teoría marxista al separar la dimensión subjetiva del aspecto objetivo en la relación capital- trabajo (Modonesi M., 2005: 100) Invierten el orden de análisis y sobredimensionan el antagonismo y la lucha de clases por encima de las leyes objetivas que imponen las relaciones de producción y circulación capitalista. Con esto magnifican la capacidad de auto-organización de las clases populares para efectuar la transformación social sin tener que pasar por el tormentoso camino de la vía estatal- institucional. No es ocioso que Marx 
haya empezado el estudio del capitalismo por la mercancía como la categoría básica que atraviesa todos los ámbitos de la sociedad capitalista. Es precisamente la forma mercancía que adopta el producto del trabajo de los hombres, lo que se les contrapone como si fuera algo determinado por leyes sobrenaturales que los dominan y explotan. Por tanto resulta imprescindible considerar las estructuras de dominación y su reconfiguración, para entender cómo se ejerce la dominación del capital, así como sus formas más sofisticadas, refinadas y complejas de control. En otras palabras, la dimensión objetiva no puede ser ignorada en las luchas anticapitalistas y antisistémicas. A nuestro parecer estas son las consecuencias teórico/prácticas de la inversión metodológica de los autonomistas que reifican el antagonismo y la lucha como categorías heurísticas para explicar no solo el funcionamiento del capitalismo de manera parcial y unilateral, sino que exageran el papel que pueden tener los movimientos sociales como agentes de cambio para efectuar/impulsar transformaciones sociales que vayan en contra y más allá del capital y el Estado.

Por lo tanto, anteponer la lucha en lugar de las leyes objetivas impide a esta izquierda entender las reconfiguraciones que presenta el capitalismo en su etapa neoliberal actual y las relaciones internacionales de dependencia, así como la correlación de fuerzas internas que condicionan y limitan el funcionamiento interno de la periferia sudamericana. Debido a esto, los autonomistas están limitados teóricamente para explicar procesos sociales de cambio más amplios y complejos como la experiencia de los gobiernos progresistas que se presentaron en Bolivia, Ecuador y Venezuela. Ante esta incapacidad, los autonomistas positivizan a Gramsci y forzan de manera grosera y abusiva la categoría de revolución pasiva para encuadrar la realidad en la teoría y diluir todas las especificidades que se han presentado en la experiencia de cambio durante la etapa progresista en los tres países andinos. Se les olvida que estos gobiernos fueron resultado de los movimientos sociales organizados desde las bases populares que se articularon en torno a un partido político (el MAS en Bolivia, Alianza País en Ecuador, el PSUV en Venezuela) para acceder al poder político a través de procesos electorales y conformaron un nuevo Bloque Histórico de Poder que configuró una nueva hegemonía. El paso siguiente fue convocar a Asambleas Constituyentes para crear una nueva constitución, refundar el Estado y rearticular el vínculo entre sociedad política, sociedad civil y mercado. En este sentido, son procesos sociales complejos que merecen una atención escrupulosa y detallada.

\section{c. El reproche del marxismo doctrinario.}

Para la izquierda doctrinaria no habría un fin de ciclo puesto que el posneoliberalismo es una continuación de la estrategia neoliberal para estabilizar el capitalismo en América Latina pero por otros medios (Stolowicz, 2011: 31). El neoliberalismo privilegió el mercado, la privatización, la desregulación, la exaltación del discurso individualista, la contracción de la democracia, el uso patrimonialista del poder político, la concentración del ingreso, la desigualdad, el desempleo y la pobreza. El posneoliberalismo por su parte, reconfiguró al Estado para otorgarle más facultades en la regulación del mercado y la nacionalización de sectores estratégicos; impulsó programas de asistencia social para combatir la pobreza y legitimar al gobierno en turno; amplió los espacios de participación ciudadana para fortalecer la democracia y creó un consenso para incluir y equilibrar las 
diversas fuerzas políticas a fin de favorecer la gobernabilidad. Más allá de estas diferencias, para Stolowicz, neoliberalismo y posneoliberalismo son partes constitutivas de una estrategia dominante para garantizar mayores ganancias al capital en medio de la crisis. Los aparentes movimientos pendulares entre ambos no son ciclos opuestos alternativos, sino momentos distintos para acrecentar las ganancias y fortalecer el dominio del capital (Stolowicz, 2016: 1128-1129).

Para la izquierda doctrinaria, el problema de fondo de estos gobiernos de "izquierda" es que no llevaron a cabo una auténtica revolución social que modificara las relaciones sociales de explotación capitalista y aboliera la estructura de la propiedad privada sobre los medios de producción. Es cierto que las experiencias de Bolivia, Ecuador y Venezuela fueron más allá y se distinguieron por su orientación anticapitalista-neoliberal, anticolonial y pro- socialista, pero fueron revoluciones políticas que solo cambiaron el régimen político pero no transformaron radicalmente la estructura de la propiedad privada de los medios de producción. Ese es su límite, su principal frontera (Gómez Leyton, 2009: 46). Esto es lo que marcaría una diferencia sustancial entre un proceso auténticamente revolucionario y una transformación política. Para lo que denominamos marxismo doctrinario, la revolución cubana en 1959 y el gobierno de la Unidad Popular en Chile encabezado por Allende en 1970, han sido las únicas experiencias de una auténtica revolución social que se haya registrado en la historia de América Latina (Gómez Leyton, 2009: 67)

Advertimos tres falencias en los anteriores razonamientos. En primer lugar, al partir de la caracterización del posneoliberalismo como una etapa exitosa de reestructuración capitalista, desarticula teoría y praxis y es incapaz de explicar las particularidades y condiciones específicas concretas de las experiencias de cambio en Bolivia, Ecuador y Venezuela que no solo superaron el neoliberalismo, sino representaron un verdadero hito en la construcción histórica, política y teórica de una nueva forma de Estado Nación y de Democracia que significó una ruptura con las formas históricas, jurídicas y políticas de matrices eurocéntricas impuestas y heredadas durante los últimos dos siglos (Gómez Leyton, 2017: 17-18). En segundo lugar, esta izquierda se abstrae de las mutaciones que experimenta el capitalismo en su etapa neoliberal actual para condicionar el funcionamiento de la periferia a partir de una Nueva División Internacional del Trabajo (NDIT) que responde a las necesidades del capital financiero y las Empresas Trasnacionales (ETN’s). Por más revolucionario que sea un gobierno de izquierda es imposible que en las condiciones actuales pueda superar el capitalismo ya que implicaría transformar de fondo las relaciones internacionales de dependencia. En tercer lugar, al quedarse en el contexto de la guerra fría, la izquierda doctrinaria mistifica experiencias de cambio social tomando como paradigma los casos de la revolución cubana y el Gobierno de la UP en Chile para ejemplificar procesos auténticamente revolucionarios. Olvida que el derrumbe soviético cambió radicalmente la correlación mundial de fuerzas. Observamos el desfase ya mencionado entre filosofía y política, entre teoría y realidad.

$\underline{\text { 3. Viviendo el reino de la necesidad: los límites geopolíticos del progresismo }}$ latinoamericano. 
El derrumbe soviético obliga a replantear el clásico debate entre reforma y revolución, vía armada y vía institucional para dar cuenta de la forma particular en la que se llevó a cabo el cambio social en las experiencias progresistas más avanzadas en un contexto global totalmente distinto al de la guerra fría. En los tres países andinos se presentó una forma particular de efectuar la revolución: fue al mismo tiempo insurreccional y violenta pero también fue institucional, pacífica y democrática. (Gómez Leyton, 2017: 24).

a. Actualidad de la revolución y caducidad de la revolución clásica en la posguerra fría.

El "siglo XX corto" abierto por la primera guerra mundial y la revolución rusa que le siguió se cerró con el derrumbe soviético en 1991 (Hobsbawn, 1999: 11-26). Tal derrumbe de manera inevitable hizo desaparecer del imaginario mundial el horizonte socialista y la idea de la actualidad de la revolución en el sentido de su inminencia y de manera injustificada la de su necesidad (Lukács, 2004: 14-19). También cuestionó profundamente la idea clásica de la revolución tal como se había venido gestando desde la revolución francesa de 1789.

Durante buena parte del siglo XX, la izquierda visualizó un horizonte poscapitalista y la actualidad de la revolución como inminencia y necesidad. La revolución rusa de 1917, la expansión soviética en Europa oriental, la revolución china de 1949, los movimientos victoriosos de liberación nacional en África y Asia, las luchas obreras en Europa y otras partes del mundo, la revolución cubana en 1959 y la nicaragüense en 1979 consolidaron esas expectativas. La existencia de un importantísimo bloque de países, territorio y población que vivía bajo el socialismo real consolidó la idea de que se observaba una época de transito del capitalismo al socialismo. La existencia de una desigualdad entre estratos poblacionales y entre países, la presencia de una gran pobreza y expoliación en el planeta, la hegemonía imperial estadounidense, fueron hechos que fundamentaron la actualidad de la revolución como necesidad ineludible y como inminencia aunque esta última fuera medida en tiempo histórico y no en la de la vida de un ser humano.

El derrumbe soviético se vio acompañado también por el auge neoliberal. Ese auge habría de provocar una severa crisis a la socialdemocracia clásica que dio paso a una nueva socialdemocracia neoliberalizada y bautizada como "tercera vía". La noción de "actualidad de la revolución" enarbolada por Lenin en toda su obra y por Gramsci en la suya (Arismendi, 1976: 18-20; Macciocchi, 1980: 47-77) se vio desvirtuada en el sentido de su inminencia aun cuando no en el de su necesidad. No podía alegarse ya que el mundo vivía una transición al socialismo y que estaba cercana la revolución. Pero el derrumbe soviético no descartó la necesidad de una revolución poscapitalista en tanto que lo que sucedió a dicho derrumbe fue la implantación de lo que se llamó "capitalismo salvaje" o "capitalismo sin bridas", diferente a lo que Harvey llamó "liberalismo con bridas" (Harvey, 2007: Cap. I).

El cambio de correlación de fuerzas en el mundo en la posguerra fría y el desarrollo de una tecnología militar sofisticada en los países centrales, también provocó la caducidad de la noción clásica de revolución. En términos generales puede decirse que en el momento actual, no hay posibilidades de una revolución a través de una vía violenta, ni 
tampoco de una revolución que de manera acelerada haga transformaciones capitalistas. Marx y Engels en El Manifiesto Comunista (Marx y Engels, 1848/1971) y en otros escritos y Lenin en su obra militar (Lenin, 1906/1977; 1917a/1977) concibieron a la insurrección armada como el escenario más probable para la conquista del poder. Posteriormente, Mao habría de introducir una variante de esa vía violenta con la noción de "guerra popular y prolongada" (Mao, 1938b/1972) al igual que el general vietnamita Giap con la de "guerra de todo el pueblo" (Giap, 1971). Finalmente la experiencia cubana habría de ser sistematizada con la idea del "foco revolucionario" de Ernesto Che Guevara (Guevara, 1960, 1963, 1964).

En lo que se refiere al carácter de la revolución, la izquierda mundial la imaginó como una revolución orientada al socialismo y con una etapa inicial democrática nacional (Lenin, 1905a/1961) o bien como una revolución definidamente socialista desde el principio (Lenin, 1918/1961; Trotsky, 1929/2000-2002), en todo caso como una revolución con embates acelerados contra el capital y cambios radicales desde el principio (Marx y Engels, 1848/ 1971).

Después del derrumbe soviético la transformación social se imaginó de otra manera. La vía de la misma sería una de carácter pacífico a través de la participación electoral y el objetivo sería el desmantelamiento paulatino del capitalismo neoliberal. La revolución no sería un acto concentrado en poco tiempo sino un proceso dilatado en el mismo. El objetivo no sería socialista sino un orden posneoliberal. Si se planteaba el socialismo, este sería más que construcción del presente, un horizonte estratégico que no repetiría al socialismo del pasado: sería el "socialismo del siglo XXI". Esta concepción planteada sucintamente es la que animó a las fuerzas progresistas de voluntad posneoliberal, las cuales paulatinamente fueron conquistando gobiernos a través elecciones y reelecciones entre 1999 y 2015.

El derrumbe soviético y el auge neoliberal crearon una nueva correlación de fuerzas y anclaron aún más a la utopía socialista o poscapitalista al reino de la necesidad. Por esta última entendemos al mundo lleno de obstáculos y límites de diverso tipo que ensanchan notablemente la brecha entre lo posible y lo deseable.

\section{b. La jaula de hierro de la Nueva División Internacional del trabajo (NDIT).}

La crisis del dólar de 1971 marcó el fin del modelo de acumulación fordista. Esta situación obligó a las ETN's a modificar su estrategia de producción a escala global mediante la fragmentación de las diferentes fases del proceso de producción, así como su deslocalización y externalización en otros países o regiones fuera de los centros industriales para crear Cadenas Globales de Valor (CGV) con la finalidad de reducir costos de producción y aumentar sus ganancias (Kreimerman, 2017: 6). Las ETN’s líderes se enfocan sobre el diseño, desarrollo de producto y mercadotecnia, mientras que subcontratan la manufactura en grandes cantidades con proveedores independientes o crean clusters industriales dirigidos por sus propias filiales en países emergentes. Para llevar a cabo la deslocalización, las ETN’s líderes consideran entre otros aspectos: la dotación de mano de obra barata, acceso a recursos naturales abundantes, financiamiento, 
disponibilidad de tecnología con recursos técnicos capacitados y cercanía con los mercados de consumo. (Salama, 2012: 69).

Las nuevas tecnologías de la información y el conocimiento (TIC's) facilitaron la movilidad de las ETN’s más allá de las fronteras nacionales para crear e integrar clusters especializados que les permitieran disminuir tiempos y costos tanto en la producción como en la comercialización. De la misma manera, las reformas estructurales neoliberales fueron la respuesta política para readecuar el marco jurídico e institucional de los países desarrollados y emergentes a las exigencias que demandaba la reorganización industrial en las CGV. De hecho, la firma de tratados comerciales y acuerdos de integración regionales responde precisamente a la lógica de funcionamiento de éstas últimas. En lugar de que las industrias operen en un escenario local, ahora lo hacen desde una dimensión global. Esto sería lo específico de la producción global capitalista en su fase neoliberal actual: las diferentes fases del proceso de producción a nivel local se desintegran/fragmentan para dispersarse geográficamente en clusters especializados de bajo costo. Al mismo tiempo, gracias a las nuevas tecnologías de la información y la comunicación, estas distintas fases dispersas en otros territorios se reintegran/reconcentran en una cadena de valor bajo el control de las ETN’s líderes.

El resultado final de esta reorganización industrial es el surgimiento de una Nueva División Internacional del Trabajo (NDIT) en la que más que una convergencia, se está presentando una bifurcación al interior de la periferia donde se acentúa la relación de subordinación y dependencia de América Latina, África y Medio Oriente, ya no solo frente a los países desarrollados sino ante el Sudeste Asiático y China. (Belloni \& Wainer, 2014: 20). Inicialmente estaría la periferia de la periferia constituida por el África Subsahariana, Centroamérica y Medio Oriente que presentan un escaso o nulo desarrollo industrial y se insertan al mercado global mediante la exportación de productos primarios y/o mano de obra como migrantes. Después estaría la periferia semi-industrializada que presenta cierto grado de industrialización en la elaboración de productos con poco valor agregado ya que dependen de la tecnología externa. Por tanto, son países ensambladores y/o primario exportadores. Aquí ubicaríamos a Sudamérica, México, Turquía, Irán y algunas ex repúblicas soviéticas. En tercer lugar estaría la Periferia de Industrialización reciente que se concentra en la región del sudeste asiático y China. Gracias a la fuerte participación del Estado en la dirección del desarrollo nacional para sustituir importaciones, el sudeste asiático y China lograron desarrollar un aparato industrial cada vez más complejo y articulado que les ha permitido participar en las CGV con procesos de mediana y alta tecnología. Por último, los países desarrollados presentan una desindustrialización relativa pero controlan los segmentos de mayor importancia dentro de la CGV tales como el diseño, la innovación, la comercialización y el suministro de servicios relacionados con la informática, las finanzas y telecomunicaciones. (Bianchi \& Szpak, 2013: 7)

El éxito industrializador del sudeste asiático y China, así como su creciente demanda de energéticos, materias primas y alimentos para cubrir los requerimientos de su economía en constante expansión, ha profundizado el viejo modelo primario exportador en Sudamérica. Con la NDIT y el predominio del neoliberalismo a escala global, en esta 
región se ha impedido el desarrollo de una estructura industrial relativamente integrada en la que el capital nacional detente y oriente el desarrollo de las fuerzas productivas en función de las condiciones internas y externas que enfrentan los países sudamericanos. Sucede lo contrario, el patrón de acumulación que se sustenta en la explotación de recursos naturales queda determinado por las necesidades de la acumulación del capital que imponen las ETN’s a través de las CGV.

Si bien es cierto que el neoliberalismo presentó síntomas de agotamiento desde la década de los noventa del siglo pasado y comenzó a ser sustituido en la región sudamericana por gobiernos de izquierda en el siglo XXI, los nuevos proyectos se erigen sobre las bases creadas por éste patrón de acumulación: la gran concentración del capital, la hegemonía del capital transnacional en la mayoría de los países de la región y una creciente dependencia de la producción de commodities para la exportación. Pero habría que diferenciar la manera cómo se insertan los países sudamericanos en la NDIT según la orientación política de sus respectivos gobiernos. El caso de Chile, Perú y Colombia mantienen una fe ciega hacia los lineamientos del libre mercado para incentivar el crecimiento económico y otorgarle un mayor peso al capital extranjero en las decisiones políticas internas. Otro grupo de países como Brasil, Argentina y Uruguay implementaron un proyecto neodesarrollista recuperando el papel del Estado en la dirección y fomento del desarrollo mediante políticas heterodoxas y redistribuyendo una parte de los excedentes generados por las actividades primarias hacia los grupos sociales más vulnerables. ${ }^{3}$

Finalmente están los gobiernos progresistas de izquierda más radicales en Bolivia, Ecuador y Venezuela, donde se presentaron procesos de cambio social más complejos y profundos. Gracias a la re-estatización de sus sectores estratégicos y con regulaciones más estrictas hacia el capital trasnacional, se logró ganar espacios de soberanía al apropiarse de una mayor parte del excedente generado por las actividades extractivistas. Sin embargo, a pesar de los avances en infraestructura e industrialización de materias primas, no se ha logrado superar el modelo primario exportador. Lo anterior no es por falta de voluntad política, sino porque el contexto internacional impone fuertes restricciones al funcionamiento interno de estos países. Resulta extremadamente complicado que un solo país o un grupo de países puedan "aislarse o desconectarse" de la economía mundial, o bien que transformen por sí solos la NDIT que los condiciona a especializarse en la extracción/exportación de materias primas.

\section{c. China y la reprimarización de América del Sur.}

En la década de los setenta, China experimentó un fuerte estancamiento económico que obligó a los miembros del Partido Comunista Chino a cambiar el modelo de desarrollo. La muerte de Mao Zedong y el ascenso de Deng Xiaoping posibilitó a partir de 1978 un

\footnotetext{
${ }^{3}$ Esta aseveración hay que matizarla a la luz de los acontecimientos observados en los últimos años. Brasil dio un vuelco a la derecha con Bolsonaro (2019), mientras en Chile (a partir de 2019) y Perú (2021) observamos una tendencia inversa. Cabe seguir observando el curso de las protestas sociales en Colombia observadas en 2018 y 2021.
} 
cambio que fue denominado "socialismo con peculiaridades chinas". Esto último no fue más que acelerar el desarrollo de las fuerzas sociales productivas de manera capitalista pero bajo la estricta conducción estatal. Lo peculiar de esta estrategia es que el poder político no lo tiene la gran burguesía que surgió de este proceso sino el Partido Comunista y el gobierno que dirige. Por lo tanto la estrategia de desarrollo queda supeditada a un objetivo socialista. (Figueroa Ibarra, 2019)

Las reformas económicas de 1978 introdujeron un sistema de responsabilidad individual en la producción agrícola, las empresas estatales se convirtieron en compañías divididas por acciones y se flexibilizó la contratación de mano de obra para aumentar la productividad. Asimismo el gobierno chino diseñó Zonas Económicas Especiales en su costa sur para repatriar a los empresarios de origen chino que radicaban en el sudeste asiático y que contaban con amplia experiencia en los negocios, así como para atraer a las ETN's que contribuyeran a la transferencia tecnológica y a la producción de bienes industrializados para la exportación (Arrighi, 2007: 366). Gracias a estas reformas China se convirtió en el taller manufacturero del mundo, desarrollando un sector de alta tecnología que ha posicionado a Huawei y Lenovo como empresas de clase mundial. De hecho, ETN's como Microsoft, Oracle, IBM, Siemems, Apple, VW, etc., han trasladado parte de su actividad de investigación y desarrollo hacia China para aprovechar su gran reserva de científicos cualificados pero baratos, de la misma manera han deslocalizado fases de su proceso de producción para aprovechar las ventajas de su extenso mercado interno y su abundancia de mano de obra barata. (Harvey, 2007: 137).

En China se puede llevar a cabo el mismo proceso productivo sin una fuerte inversión de capital gracias al creciente aumento de ingenieros, científicos y técnicos que facilitan no solo la sustitución de máquinas y supervisores por trabajo calificado barato, sino que también mejoran la división social del trabajo hacia la producción intensiva en conocimiento e innovaciones. De esa manera, los ahorros en los bajos costos de mano de obra se traducen en amplios márgenes de ganancia para las empresas (Harvey, 2007: 147). Estos logros no se podrían explicar tan solo por las reformas económicas de 1978, sino que se apoyaron sobre las bases que dejó la Revolución Cultural de Mao en educación, salud y alimentación (Arrighi, 2007: 366). Las reformas de 1978 alentaron un rápido proceso de urbanización que demandaba una fuerte inversión en capital fijo para construir nuevos sistemas de metros, autopistas, vías férreas y aeropuertos (Harvey, 2007: 137). Todos estos cambios permiten entender el espectacular crecimiento económico que ha registrado China desde la década de los noventa del siglo pasado y su alta dependencia hacia fuentes extranjeras de recursos naturales que le garanticen mantener en el tiempo sus elevadas tasas de crecimiento.

El proceso de reproducción del capital en China se convirtió en un factor clave para la reprimarización de América Latina, principalmente de la región sudamericana. Con los altos niveles de competitividad y productividad que presenta China, varias empresas y cadenas industriales locales en América Latina se han desarticulado o desmantelado. La inversión productiva se ha canalizado hacia la extracción de recursos naturales para su exportación, en especial hacia el mercado chino. Esto se puede apreciar con la descripción de los flujos de intercambio comerciales que se establecen entre China y los tres países 
andinos con gobiernos progresistas: Bolivia, Venezuela y en su momento Ecuador. Básicamente estos países concentran su cesta exportadora en materias primas sin incorporar valor agregado: petróleo crudo, minerales sin procesar -estaño, zinc, plomo, cobre, etc.-, y alimentos tanto crudos como procesados. En cambio China exporta hacia los tres países andinos una canasta muy diversificada de productos industrializados de alta, mediana y baja tecnología: bienes de capital (maquinaria y equipo), bienes de consumo duradero (automóviles, dispositivos electrónicos, electrodomésticos, etc.) y bienes intermedios (artículos de hierro y aluminio, plásticos, fertilizantes, etc.). Por tanto, durante todo el periodo progresista que coincide con la emergencia de China como el taller manufacturero del mundo a partir del año 2000, se registró un saldo comercial superavitario muy favorable al país asiático. Situación que prevalece en la actualidad (COMTRADE, 2020).

La excepción es el déficit en balanza comercial que registró China con respecto a Venezuela durante el periodo del 2008 al 2017, situación que refleja la gran dependencia de China por el petróleo venezolano. Los mayores acuerdos de inversión que negoció China en América Latina, fueron con Venezuela para participar en el control de la mayor reserva de petróleo del mundo (Bruckman, 2012: 124). Sin embargo esta circunstancia reprimariza a Venezuela ya que es altamente dependiente de los productos industrializados básicos que requiere la población.

En síntesis, los efectos que generan las relaciones comerciales entre China y América Latina, incluyendo los países con gobiernos progresistas, son: “...la reprimarización de las exportaciones y de la estructura económica, déficit comerciales significativos en productos de mediana y alta intensidad tecnológica (asociados a la dependencia de la oferta externa en bienes de capital e insumos), desintegración de las cadenas productivas, reducción del comercio regional, y perdida de participación en terceros mercados." (Bekerman, Dulcich, \& Moncaut, 2014, p. 79). Y como lo subraya la CEPAL: "la persistencia de un marcado patrón primario exportador hacia América Latina condiciona los intentos de los gobiernos de la región por avanzar hacia una estructura productiva y exportadora más diversificada, intensiva en conocimiento y social y ambientalmente sostenible" (CEPAL, 2015)

En consecuencia, la relación internacional que se establece entre China y los países con gobiernos progresistas -y en general con toda América Latina- reproduce las tradicionales relaciones de dependencia que se establecen entre el centro y la periferia. Sin bien hay un beneficio a corto plazo con el aumento de los precios de las materias primas y un mayor ingreso derivado de las exportaciones de recursos naturales, a largo plazo la relación con China profundiza el extractivismo y el carácter rentista/consumista de las economías latinoamericanas. Por lo tanto, cualquier posibilidad de cambio o transformación social necesariamente tiene que contemplar la relación comercial con el "socio chino" y la situación de dependencia que se derivan de estos intercambios. Por ello resulta bastante problemático pensar en "alternativas al desarrollo" -el buen vivir o el suma kawsay, por ejemplo-, "transformar el mundo sin tomar el poder", o bien efectuar "la revolución radical socialista" sin considerar el vínculo económico y político tan fuerte que se ha establecido entre China y Sudamérica. Al no considerar esta situación, las críticas de la 
izquierda latinoamericana hacia el desempeño de los gobiernos progresistas y su planteamiento del fin de ciclo, así como sus alternativas de cambio social quedan sin un sustento real al moverse en la abstracción y el voluntarismo.

\section{d. Lloviendo sobre mojado: Brasil y la profundización de la dependencia .}

La crisis de 1929 abrió la posibilidad de que Brasil y otros países de América Latina iniciaran procesos de industrialización para producir internamente bienes manufacturados que se dejaron de recibir por la recesión económica que afectaba a los países industrializados. La estrategia consistió en implementar un modelo de sustitución de importaciones para fabricar internamente bienes de consumo final y desarrollar una planta productiva industrial articulada. El Estado brasileño jugó un papel fundamental al otorgar facilidades crediticias para la conformación de empresas privadas nacionales o apoyar a las ya existentes, exentando o reduciendo impuestos, protegiendo a la naciente industria nacional mediante aranceles y un tipo de cambio sobrevaluado para disminuir la inflación y abaratar importaciones en insumos procesados y bienes de capital que requería la industrialización. En el contexto de avances sustanciales en la sustitución de importaciones, el resultado más importante fue el surgimiento y empoderamiento de una nueva burguesía industrial brasileña que disputó el control del poder político y económico a la antigua oligarquía terrateniente y al capital extranjero que predominaban en el modelo primario exportador (Marini, 1980: 29-33).

Posteriormente, la dictadura militar que se instauró a raíz del golpe de Estado de 1964 anunció la aplicación de las primeras medidas de estabilización y ajuste estructural de corte monetarista. La dictadura militar enfrentó la crisis política con la represión policiaca en contra de los movimientos populares y activistas sociales, así como anulando garantías al respeto de los derechos individuales. En el ámbito económico las medidas se encaminaron a aumentar la tasa de explotación con la contracción salarial, la restricción del crédito y el aumento de la carga tributaria. Asimismo se utilizó la deuda estatal como palanca para impulsar el crecimiento económico a través de grandes obras de infraestructura que fueron realizadas por tres de las principales constructoras de Brasil: Odebrech, Camargo Correa y Andrade Gutiérrez (Zibechi, 2012: 166). De esta manera se favoreció la concentración de la riqueza en manos de las clases sociales más poderosas de Brasil: comerciantes, terratenientes, el capital extranjero-principalmente norteamericano- y sobre todo de la burguesía industrial y financiera emanada del modelo de Industrialización por sustitución de importaciones (ISI) (Marini, 1980: 57)

Con el retorno de la democracia a Brasil y la crisis de la deuda externa que afectó a toda América Latina a principios de los 80’s del siglo pasado, se implementó el modelo neoliberal que impulso el proceso de concentración y centralización de las grandes empresas brasileñas. Tal como sucede en Latinoamérica, las empresas estatales brasileñas que controlaban sectores clave para el desarrollo nacional -petroquímica, siderúrgica, minería, alimentos, comunicaciones, etc.-, se privatizaron y pasaron a manos de importantes capitales nacionales privados que se convirtieron en grandes conglomerados empresariales al diversificar sus inversiones en distintas ramas económicas: industria, banca, comercio, agricultura y sectores extractivistas. Todo esto favoreció el surgimiento 
de poderosas ETN's brasileñas que disputan el control de mercados y fuentes de abastecimiento de materias primas en Sudamérica

El proceso de internacionalización de los monopolios brasileños continuó con los gobiernos del PT. En esta etapa fue fundamental el papel que desempeñó el Banco Nacional de Desarrollo Económico y Social (BNDES) -el principal banco de desarrollo de Brasil que maneja los fondos de pensiones de los trabajadores-, para financiar y contribuir al reposicionamiento ventajoso de las ETN's brasileñas en el control de determinadas etapas del proceso productivo en las cadenas globales de valor. ${ }^{4}$ Es falso que estas empresas hayan sido engendradas durante la etapa progresista de los gobiernos de Lula. Más bien son empresas que -como hemos explicado-, surgen de todo un proceso de acumulación, concentración y centralización del capital que comienza desde el modelo ISI, se refuerza con la dictadura militar y se apuntala con el modelo neoliberal. En todo caso el gobierno de Lula se enfrentó a una poderosa oligarquía brasileña ya consolidada, encabezada por la burguesía industrial y financiera que es imposible de doblegar y con la que tiene que negociar la implementación de políticas redistributivas a favor de los más desprotegidos por el neoliberalismo.

A pesar de llegar a la etapa caracterizada por la conformación de monopolios y la exportación de capitales, Brasil no pudo dejar de ser un país dependiente y subdesarrollado. Efectivamente, aunque el proceso de industrialización brasileño avanzó en la articulación de cadenas productivas, no dejó de ser dependiente de insumos y tecnología importada por el capital extranjero que es por definición ahorradora de mano de obra. Aplicadas en el contexto social brasileño de fuertes oleadas de migración rural hacia la ciudad, estas tecnologías provocaron el incremento del desempleo y la reducción salarial. En este sentido, el mercado interno se comprimió y una parte importante de las mercancías elaboradas internamente fueron dirigidas hacia los estratos sociales de más altos ingresos, dificultando con ello la realización de la plusvalía generada en la producción. Ante este corto circuito o divorcio entre producción y circulación del capital en Brasil, la salida ha sido la exportación de capitales y el control de mercados de sus vecinos regionales en Sudamérica. (Marini, 1978: 54; Marini, 1980: XXII)

De esta manera, la burguesía brasileña en alianza con el capital extranjero continuaron con la concentración y centralización del capital. Al interior de Brasil con la superexplotación de la fuerza de trabajo y de sus recursos naturales. Externamente con la conquista de nuevos territorios y mercados a través de la exportación de capitales. Y es precisamente esta forma tan particular de acumular el capital en Brasil que lo condiciona para operar como subcentro o como una suerte de subimperialismo que influye a su vez sobre el funcionamiento interno de sus vecinos regionales (Marini, 1980: 79)

\footnotetext{
${ }^{4}$ Empresas como Jbs- Friboi (alimentos cárnicos y sus derivados), Gerdau (metalurgia), Odebrecht (construcción), Metalfrio (electrónica); Ibope (servicios); Andrade Gutiérrez (construcción), Vale (minería), Ambev (cervezas), Marco Polo (Vehículos), entre otras, reciben un impulso adicional en su proceso de transnacionalización con los gobiernos del PT. (Zibechi, 2012: 165)
} 
Lo anterior se puede explicar a partir de los flujos comerciales que se establecen entre Bolivia, Ecuador y Venezuela con respecto a Brasil: Bolivia exporta petróleo crudo, gas natural y electricidad; Ecuador concentra sus ventas en alimentos naturales y minerales sin procesar; Venezuela es un exportador neto de petróleo crudo. Por su parte, Brasil exporta hacia los tres países andinos alimentos procesados: carne y productos de origen animal; insumos industriales: sustancias químicas, artículos de plástico, colorantes, piezas de hierro y acero; bienes de capital: maquinaria y equipo; bienes de consumo duradero: automóviles, calzado, equipo médico y productos farmacéuticos. En consecuencia debido a su cesta muy diversificada de exportaciones, Brasil registra saldos comerciales muy favorables con respecto a los tres países andinos. La excepción fueron los déficits que registró Brasil con respecto a Bolivia del 2003 al 2016 debido a la alta demanda de energéticos bolivianos necesarios para impulsar la industrialización del norte de Brasil (COMTRADE, 2020).

De esta manera, la presencia de Brasil como potencia intermedia es otro factor adicional que complejiza el contexto internacional al cual se han enfrentado no solo los tres países andinos con gobiernos progresistas, sino el resto de la periferia sudamericana ya que condiciona su funcionamiento interno como economías primario exportadoras y al mismo tiempo los vuelve altamente dependientes de los insumos necesarios para llevar a cabo cualquier esfuerzo para diversificar su matriz productiva y superar el extractivismo.

$\underline{\text { 4. El optimismo de la voluntad y el pesimismo de la inteligencia: reinventado la }}$ revolución en el patio trasero del imperio estadounidense.

Con la reestructuración de los procesos de producción en las CGV, la emergencia de China como potencia mundial y la expansión del neoliberalismo a escala global, se han erosionado las bases que hicieron posible el orden mundial capitalista de posguerra encabezado por Estados Unidos de América. Es cierto que EUA sigue teniendo un papel importante en el sistema internacional de poder, pero lo hace más por la fuerza y la coacción-económica, financiera, política y militar- que por su hegemonía. La decadencia estadounidense como la de los imperios precedentes explica la acentuación de su agresividad e inmoralidad (Borón, 2012: 48)

Debido a esto hay un temor manifiesto entre la clase dominante de EUA -concentrada en el complejo militar, industrial y financiero- a perder sus privilegios ante el debilitamiento de su país. Como respuesta a esta situación, la oligarquía estadounidense reacciona apelando cada vez más al uso de la fuerza militar, a la restricción de las garantías individuales y las libertades democráticas, a la manipulación ideológica a través del control de la poderosa industria cultural para inducir un sesgo conservador, racista, machista entre la población blanca norteamericana de clase media. En el ámbito externo, EUA busca desestabilizar gobiernos de izquierda que representen una amenaza a sus intereses nacionales vitales. Este es un elemento que contribuye a explicar el auge del conservadurismo y el neofascismo a escala global, y representa un factor adicional para complejizar el contexto internacional al cual se enfrentan los gobiernos progresistas en Sudamérica 
Bajo este escenario, América Latina, y en especial la región sudamericana -gracias a su notable abundancia de riquezas naturales- se encuentra en medio de una disputa geopolítica entre los grandes centros de poder imperiales y sus empresas trasnacionales (ETN's) para apropiarse de sus fuentes de materias primas que son estratégicas en un entorno altamente competitivo y de agotamiento de recursos naturales no renovables de energía. Además de contar con las mayores reservas de agua dulce del planeta, Sudamérica cuenta con importantes yacimientos de minerales que son insumos fundamentales de los sectores más dinámicos de EUA: industria militar, aeroespacial, satelital, automotriz, nanotecnología (Bruckman, 2012: 36-38). Específicamente en lo que se refiere al intercambio comercial entre Bolivia, Ecuador y Venezuela con respecto a EUA, Bolivia exporta hacia Norteamérica minerales sin procesar y alimentos naturales y procesados; Ecuador concentra sus exportaciones en petróleo crudo, alimentos naturales y minerales sin procesar; mientras que Venezuela es un exportador neto de petróleo crudo sin procesar. Por su parte, EUA exporta hacia los tres países andinos combustibles procesados: gasolina y diesel; bienes de capital: maquinaria y equipo; bienes de consumo duradero: vehículos, equipo de transporte, dispositivos electrónicos, aparatos médicos; y bienes intermedios de uso industrial tales como sustancias químicas y piezas de plástico. Sin embargo, a pesar de la diversidad de su canasta exportadora con bienes de alto, medio y bajo valor agregado, EUA registra constantes déficits comerciales con los tres países andinos a partir de 1998. Esta situación se acentuó durante la crisis de los préstamos hipotecarios subprime en 2007-2008 y tendió a disminuir en 2013 con la recesión de la economía mundial (COMTRADE, 2020). Esto no hace más que reflejar la alta dependencia que tiene EUA de los recursos naturales de Sudamérica para garantizar los niveles de producción interna que le permitan mantener la calidad de vida de su población. Como es sabido, ésta es determinada en gran medida por el bombardeo publicitario del american way of life sustentado en el consumismo y el despilfarro (Borón, 2012).

Otra implicación política que se deriva del déficit comercial que registra EUA frente a los tres países andinos con gobiernos progresistas, es la urgente necesidad que tiene el imperio estadounidense de establecer alianzas y acuerdos con los sectores de derecha más radicales para patrocinar e impulsar la caída de estos regímenes de izquierda por cualquier medio, sea ilegal o legal. Los mecanismos de presión se han diversificado y aparte del recurso de la fuerza y la violencia física, EUA también recurre a la persuasión y la distracción del sentido común a través de un discurso ideológico conservador que llegó a ser fascistoide con Trump. También se emplea la manipulación de la información en los medios internacionales de comunicación y no se escatima en recurrir a los golpes parlamentarios para derrocar gobiernos legítimamente electos a través de la vía "legal y pacífica". La derecha sudamericana, siguiendo las instrucciones de Washington, también busca evitar a toda costa que la izquierda vuelva al poder y ha desplegado una campaña de persecución política y judicial (Lawfare) en contra de líderes progresistas que pueden volver a ser una opción política frente al fracaso que produce el restablecimiento del antiguo modelo neoliberal. Este régimen es el que más le conviene a EUA para salvaguardar sus intereses de seguridad nacional en Sudamérica. 
En el fondo, la política exterior de Estados Unidos al establecer alianzas y pactos bilaterales con sus "socios" sudamericanos -Colombia, Perú, Chile- es para tener gobiernos locales favorables a sus intereses y que les permitan la instalación de bases militares no convencionales. Es decir, centros de operación con equipos muy sofisticados de radiotransmisión y radares para obtener información detallada sobre la dotación de recursos naturales con los que cuenta Sudamérica, así como también para detectar los posibles movimientos populares locales que surgen en defensa de los recursos naturales para su represión y control. (Ceceña, 2008). Esta estrategia reaccionaria y contrainsurgente que despliega Washington en Sudamérica es disfrazada por el discurso de la lucha contra el terrorismo, el narcotráfico, la defensa de la libertad y la justicia, y el respeto a la democracia. El caso más paradigmático es el acecho que ha desplegado el imperialismo estadounidense para acorralar, asfixiar y desestabilizar al gobierno bolivariano de Venezuela con el objetivo de propiciar su caída. En su momento el entonces presidente Hugo Chávez se percató de que las ventas externas del petróleo venezolano estaban muy concentradas en EUA, por lo que trató de diversificar el mercado externo mediante la firma de acuerdos comerciales y financieros con China, Rusia y Brasil. Sin embargo, esto propició una mayor agresividad de la Casa Blanca porque no está dispuesta a perder el control sobre la mayor reserva de petróleo del mundo. Por tanto "si hubiera un "cambio de régimen" en Venezuela y se constituyera un gobierno "amigo" de Estados Unidos, como el de Colombia y Chile, el abastecimiento petrolero sería mucho más seguro y no habría necesidad de tocar las reservas propias. De ahí la excepcional importancia que Washington le asignó a la desestabilización y el desplazamiento de Hugo Chávez del poder, por las urnas o por cualquier otro medio (Borón, 2012: 130).

La estrategia estadounidense y de las derechas locales ha sido el neogolpismo o "golpe suave o blando" abandonando el tradicional golpe militar. Esto fue lo que observamos en Honduras y Paraguay en 2009 y 2012 y con el uso de la guerra judicial o Lawfare, la utilización del poder legislativo, la guerra mediática, el financiamiento de partidos ultraderechistas o derechistas se combina con la manifestación callejera a menudo de carácter violento (las guarimbas venezolanas por ejemplo). El neogolpismo tuvo sus primeras manifestaciones en Honduras, Paraguay y Brasil merced a los golpes de 2009, 2012 y 2016. El uso de masas en la calle con afanes neogolpistas lo observamos en Venezuela a partir de 2014 y particularmente a partir de 2015 cuando el chavismo perdió la mayoría en la Asamblea Nacional. También lo vimos en Nicaragua en 2018 y 2019 y muy particularmente en Bolivia en los prolegómenos del golpe de estado de octubre de 2019. Embozados en la lucha "por la democracia y contra las dictaduras populistas" lo que está operando en realidad son los intereses de los sectores más poderosos de la clase dominante que han perdido el control del gobierno y los de carácter imperialista que han perdido el control de recursos naturales estratégicos como el petróleo, el gas, el agua, estaño, litio, tungsteno, hierro, antimonio, cobre, plata, oro y zinc (Roitman, 2017; Brooks, 2017; Golinger, 2014; Moreno y Figueroa, 2019, Martínez 2019; Jalife Rahme, 2019).

De este modo, la influencia exterior de E.U. y las alianzas que establece entre las oligarquías locales sudamericanas para implementar gobiernos con orientación fascista y 
ultraconservadora, se convierte en un factor importante para acentuar la condición de exportadores de materias. Además los convierte en campos de operaciones de las grandes multinacionales para la explotación de sus recursos naturales. En consecuencia, se consolida la desigualdad y polarización social que sin industria ni ampliación del mercado interno acentúan su condición dependiente hacia los centros imperiales de poder (Borón, 2012).

\section{Palabras finales.}

El derrumbe soviético y el auge neoliberal observado a principios de la década de los noventa del siglo XX tuvieron un efecto brutal en los paradigmas revolucionarios de carácter socialista en el mundo entero. Debates que habían originado agrias disputas ideológicas y políticas quedaron rebasados inmisericordemente. Al parecer dejó de ser relevante la diferenciación entre reforma y revolución o al menos se tuvo que examinar tal oposición con nuevos ojos. La misma idea de revolución como un hecho inminente (la "actualidad de la revolución") fue cuestionada. Por lo tanto su noción misma fue sometida a una revisión sin que los hacían esta revisión temieran el ser acusado de revisionistas porque tal calificativo había perdido fuerza anatemática. De igual manera se volvieron añejos los debates sobre clases dirigentes y fuerzas motrices de la revolución, la centralidad del proletariado, la idea de vanguardia, el carácter de la revolución más próxima, la diferenciación entre vía pacífica o violenta de la transformación social, el papel de la lucha armada y si esta debería asumir la forma del foco insurreccional, la guerra popular prolongada o la guerra popular revolucionaria. El mismo imperialismo como categoría de análisis fue cuestionada con respecto a su pertinencia en el mundo de la globalización entre otros hechos porque se arguyó una descentralización de la dominación mundial. La idea de desarrollo fue sometida también a una implacable revisión crítica y por tanto uno de los supuestos de la teoría de la dependencia también fue fuertemente cuestionado.

Este es el contexto en el que surgen los nuevos debates sobre el sentido de la transformación esencial del orden que ha impuesto el neoliberalismo. Este trabajo es una suerte de continuidad y ruptura con respecto los debates que antaño presenció la izquierda a nivel mundial. Como puede verse a lo largo de las páginas anteriores, los debates anteriores han sido sustituidos por los que observamos entre la izquierda posextractivista/posdesarrollista, la autonómica y aquella izquierda que tiene todavía fuertes resabios de la que caracterizó a la que existía antes del derrumbe soviético y auge neoliberal. Nuestra postura en las páginas precedentes expresa la que se ha articulado en el amplio y heterogéneo abanico de fuerzas que sostienen los bloques históricos que con avances y retrocesos se han observado en aquellos países en los cuales han existido o existen gobiernos posneoliberales. Particularmente nos identificamos con la izquierda posneoliberal con horizonte socialista. Es desde esta perspectiva que nos hemos permitido pronunciar sobre las diferentes críticas que desde la izquierda se han hecho a los gobiernos progresistas. He aquí pues, nuestro planteamiento y nuestra convicción. 
Papeles de Trabajo No 42 - Diciembre 2021 - ISSN 1852-4508

Centro de Estudios Interdisciplinarios en Etnolingüística y Antropología Socio-Cultural

Bibliografía.

Acosta, A. (2011). Extractivismo y neoextractivismo: Dos caras de la misma maldición. En M. Lang, \& D. Mokrani, Más allá del desarrollo (p. 93-118). Quito (Ecuador): Fundación Rosa Luxemburgo/Abya Yala.

Arrighi, G. (2007). Adam Smith en Pekín: Orígenes y fundamentos del siglo XXI. Madrid, España: Akal.

Bekerman, M., Dulcich, F., \& Moncaut, N. (2014). La emergencia de China y su impacto en las relaciones comerciales entre Argentina y Brasil. Problemas del Desarrollo, 55-82.

Belloni, P., \& Wainer, A. (2014). La bifurcación de la periferia a partir de la internacionalización del capital: el rol de América Latina en la Economía Mundial. Consejo Nacional de Investigaciones Científicas y Técnicas (CONICET), 1- 24.

Bianchi, E., \& Szpak, C. (2013). Cadenas Globales de Producción: Implicancias para el Comercio Interncaional y su Gobernanza. Buenos Aires: FLACSO Argentina.

Borón, A. (2012). América Latina en la Geopolítica del imperialismo. Buenos Aires, Argentina: Ediciones Luxemburg.

Brooks, D. (30 de Julio de 2017). Trump amenaza con imponer más castigos sobre Venezuela. La Jornada, p. 4.

Bruckman, M. (2012). Recursos Naturales y la Geopolítica de la Integración Sudamericana. Lima, Perú: Instituto de Investigaciones Sociales Perúmundo, Fondo Editorial José Carlos Mariátegui.

Ceceña, A. E. (2007). Los paradigmas de la militarización en América Latina. Revista Em Pauta: Revista de la Facultad de Servicio Social de la Universidad del Estado de Río de Janeiro, No. 19, 57-65.

CEPAL. (2015). América Latina y el Caribe y China: Hacia una nueva era de cooperación económica. Santiago de Chile: ONU-CEPAL.

COMTRADE. (2020). United Nations Commodity Trade Statistics Dababase. Obtenido de https://comtrade.un.org

Dussel, E. (2006). 20 Tesis de Política. México: Siglo XXI Editores.

Figueroa Ibarra, C. (11 de Mayo de 2019). China, las peculiaridades de su socialismo. Obtenido de Con Nuestra América: https://connuestraamerica.blogspot.com

Garrido, J. C. (2015). “Cuadernos de la liberación”. Estudios Políticos

(Méx.) no.34 México ene./abr. 2015, 167-181 
Papeles de Trabajo No 42 - Diciembre 2021 - ISSN 1852-4508

Centro de Estudios Interdisciplinarios en Etnolingüística y Antropología Socio-Cultural

http://www.scielo.org.mx/scielo.php?script=sci_arttext\&pid=S0185-

$\underline{16162015000100008}$

Giap, V.N. (1971). Guerra del Pueblo, ejército del pueblo. Serie Popular ERA. México D.F.

Golinger, E. (24 de Octubre de 2014). El golpe suave en América Latina (I y II).

Obtenido de Actualidad RT.

https://actualidad.rt.com/opinion/eva_golinger/view/143043-agresion-permanentegolpe-suave-america-latina

Gómez Leyton, J. C. (2009). La revolución en la historia, Reflexiones sobre el cambio político en América Latina. En B. Rajland, \& M. C. Cotarelo, La revolución en el bicenternario. Reflexión sobre la emancipación, clases y grupos subalternos (p. 39- 56). Buenos Aires (Argentina): CLACSO.

Gómez Leyton, J. C. (2017). Bolivia: Un Estado, una Nación y una Democracia: ¿Poscolonial o Anticolonial? En J. C. Gómez Leyton, Bolivia Hoy: ¿Una Democracia Poscolonial o Anticolonial? (p. 11- 26). Santiago de Chile: Ediciones EscaparateCLACSO.

Gramsci, Antonio (1985). Cuadernos de la Cárcel. Editorial ERA, México D.F.

Gudynas, E. (2011). Debates sobre el desarrollo y sus alternativas en América Latina: Una breve Guía heterodoxa. En M. Lang, \& D. Mokri, Más allá del desarrollo (p. 2153). Quito (Ecuador): Fundación Rosa Luxemburgo/ Abya Yala.

Gudynas, E. (2011). El nuevo Extractivismo Progresista en América del Sur. Tesis sobre un viejo problema bajo nuevas expresiones. En V. Autores, Colonialismos del Siglo XXI (p. 75-92). Barcelona (España): Icaria.

Guevara, E. (1960/1969). Guerra de Guerrillas (1960) en Che. Ediciones Políticas, Editorial de Ciencias Sociales, La Habana.

Guevara, E. (1963/1969). Guerra de Guerrillas: un Método en Che Ediciones Políticas, Editorial de Ciencias Sociales, La Habana.

Guevara, E. (1964/1996). "Prólogo a Guerra del Pueblo-Ejército del Pueblo" en Obras Completas. Editorial Legasa, Buenos Aires.

Harvey, D. (2007). Breve Historia del Neoliberalismo. Madrid, España: Akal.

Jalife Rahme, A. (17 de Noviembre de 2019). Bolivia. Revelan plan de Estados Unidos para el golpe: nombres y apellidos, rol de la Embajada y países vecinos. Obtenido de resumenlatinoamericano: www.resumenlatinoamericano.org 
Kreimerman, R. (2017). Contexto Económico en América Latina, Perspectivas y tendencias para la transformación social- ecológica. Fundación Friedrich Ebert Stiftung, 1-30.

Marini, R. M. (1978). Dialectica de la Dependencia. México: Era.

Marini, R. M. (1980). Subdesarrollo y Revolución. México, D.F.: Siglo Veintiuno Editores S.XXI.

Mao Tse Tung (1938b/1972). Sobre la guerra prolongada. Obras Escogidas en Cuatro Tomos). Tomo II. Ediciones en Lenguas Extranjeras. Pekín.

Martínez, M. (2 de Febrero de 2019). Venezuela: Una conjetura internacional.

Obtenido de Herramienta: https://herramienta.com.ar

Marx, K. y F. Engels (1971). Manifiesto del Partido Comunista. Editorial Progreso, Moscú.

Moreno Velador, Octavio Humberto y Carlos Figueroa Ibarra (2019). "Golpismo y neogolpismo en América latina. Violencia y conflicto político en el siglo Veintiuno". Revista Iberoamérica Social, Número especial. Volumen 3. ISSN-e: 2341-0485, Sevilla, España. https://dialnet.unirioja.es/ejemplar/529779

Lenin, V.I. (1905a/1961). Dos tácticas de la socialdemocracia rusa en la revolución democrática. Tomo I de Obras Escogidas en Tres Tomos. Editorial Progreso, Moscú.

Lenin, V.I. (1906/1977). "La guerra de guerrillas" en La Lucha armada. Ediciones de Cultura Popular. México D.F.

Lenin, V.I. (1917a/1977). "El marxismo y la insurrección". En La Lucha armada. Ediciones de Cultura Popular. México D.F.

Lenin, V.I. (1917b/1961). Uno de los problemas fundamentales de la revolución. Tomo II de Obras Escogidas en Tres Tomos. Editorial Progreso, Moscú.

Lenin, V.I. (1918/1961). La revolución proletaria y el renegado Kautsky. Tomo III de Obras Escogidas en Tres Tomos. Editorial Progreso, Moscú.

Modonesi, M. (2005). Teoría y Paxis. La experiencia del obrerismo italiano. Bajo el Volcán, Vol. 5, núm. 9, 95-108.

Modonesi, M. (2015). Fin de la hegemonía progresista y giro regresivo en América Latina. Una contribución gramsciana al debate sobre el fin de ciclo. Viento Sur, 23- 30.

Modonesi, M., \& Svampa, M. (13 de Agosto de 2016). Post-progresismo y horizontes emancipatorios en América Latina. Obtenido de Rebelión : https://www.rebelion.org/

Roitman Rosenmann, M. (Agosto de 2017). Venezuela: sumisión, guerra y periodismo de encubrimiento. La jornada. 
Salama, P. (2012). Una globalización Comercial Acompañada de una Nueva Distribución Cartográfica. Revista de Economía Institucional, 57-80.

Stolowicz, B. (2011). A contracorriente de la Hegemonía Conservadora. México: Itaca/UAM- Xochimilco.

Stolowicz, B. (2016). El misterio del posneoliberalismo, Tomo II: La estrategía para América Latina. Colombia: ILSA- Espacio crítico Ediciones.

Svampa, M. (2011). Extractivismo neodesarrollista y movimientos sociales. ¿Un giro ecoterritorial hacia nuevas alternativas? En M. Lang, \& D. Mokrani, Más allá del desarrollo (p. 185- 216). Quito (Ecuador): Fundación Rosa Luxemburg/Abya Yala.

Svampa, M. (2017). Populismo latinoamericanos en el fin del ciclo progresista. Sin Permiso.

Trotsky, L. (1929/2000-2002). La revolución permanente. Proyecto Espartaco 20002002. https://www.elsoca.org/pdf/libreria/revolucion\%20permanente.pdf

Zibechi, R. (2012). Brasil Potencia. Entre la integración regional y un nuevo imperialismo. Bogotá, Colombia: Ediciones Desde Abajo.

Zizek, S. (2009). Sobre la violencia. Seis reflexiones marginales. Paidós, Barcleona/Buenos Aires/ México. 